\title{
Randomized, multicenter trial comparing sternotomy closure with rigid plate fixation to wire cerclage
}

\author{
Keith B. Allen, MD, ${ }^{a}$ Vinod H. Thourani, MD, ${ }^{\mathrm{b}}$ Yoshifumi Naka, MD, PhD, ${ }^{\mathrm{c}}$ Kendra J. Grubb, MD, \\ John Grehan, MD, PhD, ${ }^{\mathrm{e}}$ Nirav Patel, MD, ${ }^{\mathrm{f}}$ T. Sloane Guy, MD, ${ }^{\mathrm{g}}$ Kevin Landolfo, MD, \\ Marc Gerdisch, MD, ${ }^{i}$ Mark Bonnell, MD, ${ }^{j}$ and David J. Cohen, $\mathrm{MD}^{\mathrm{k}}$
}

\begin{abstract}
Objective: To evaluate sternal healing, complications, and costs after sternotomy closure with rigid plate fixation or wire cerclage.

Methods: This prospective, single-blinded, multicenter trial randomized 236 patients at 12 US centers at the time of sternal closure to either rigid plate fixation $(\mathrm{n}=116)$ or wire cerclage $(\mathrm{n}=120)$. The primary endpoint, sternal healing at 6 months, was evaluated by a core laboratory using computed tomography and a 6-point scale (greater scores represent greater healing). Secondary endpoints included sternal complications and costs from the time of sternal closure through 6 months.
\end{abstract}

Results: Rigid plate fixation resulted in better sternal healing scores at 3 $(2.6 \pm 1.1$ vs $1.8 \pm 1.0 ; P<.0001)$ and 6 months $(3.8 \pm 1.0$ vs $3.3 \pm 1.1$; $P=.0007)$ and greater sternal union rates at $3(41 \%$ [42/103] vs $16 \%$ [16/102]; $P<.0001)$ and 6 months $(80 \%$ [81/101] vs $67 \%$ [67/100]; $P=.03)$ compared with wire cerclage. There were fewer sternal complications through 6 months with rigid plate fixation $(0 \%[0 / 116]$ vs $5 \%$ [6/120]; $P=.03)$ and a trend towards fewer sternal wound infections $(0 \%$ [0/116] vs $4.2 \%$ [5/120]; $P=.06)$ compared with wire cerclage. Although rigid plate fixation was associated with a trend toward greater index hospitalization costs $(\$ 23,437$ vs $\$ 20,574 ; P=.11$ ), 6-month follow-up costs tended to be lower (\$9002 vs $\$ 13,511 ; P=.14)$. As a result, total costs from randomization through 6 months were similar between groups $(\$ 32,439$ vs $\$ 34,085 ; P=.61)$.

Conclusions: Sternotomy closure with rigid plate fixation resulted in significantly better sternal healing, fewer sternal complications, and no additional cost compared with wire cerclage at 6 months after surgery. (J Thorac Cardiovasc Surg 2017;153:888-96)

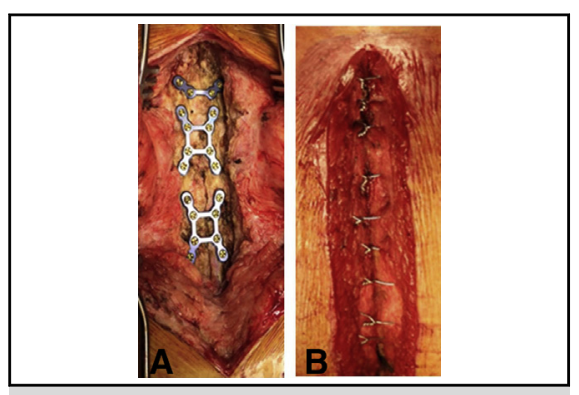

Intraoperative photograph of rigid plate fixation (A) and wire cerclage (B) patient.

\section{Central Message}

Sternal closure with rigid plate fixation resulted in improved sternal healing, fewer sternal complications, and no additional cost at 6 months compared with wire cerclage.

\section{Perspective}

In a prospective, randomized, single-blinded, multi-center trial, sternotomy closure using rigid plate fixation (RPF) compared with wire resulted in improved sternal healing and fewer sternal complications with no additional health carerelated costs at 6 months. Although the benefits of RPF are well established, this is the first randomized controlled trial that correlates RPF with improved sternal healing and outcomes.

See Editorial Commentary page 897.
Median sternotomy is the most common osteotomy and is performed in more than 500,000 patients/year in the United States alone. ${ }^{1}$ Although most surgical disciplines involved

\footnotetext{
From the ${ }^{\mathrm{a}}$ Department of Cardiothoracic Surgery and ${ }^{\mathrm{k}}$ Department of Cardiology, Saint Luke's Mid America Heart Institute and University of MissouriKansas City School of Medicine, Kansas City, Mo; ${ }^{b}$ Department of Cardiothoracic Surgery, Emory University, Atlanta, Ga; ${ }^{\mathrm{C} D e p a r t m e n t}$ of Cardiothoracic Surgery, Columbia University Medical Center, New York, NY; ${ }^{\mathrm{d}}$ Department of Cardiothoracic Surgery, University of Louisville, Louisville, Ky; ${ }^{\mathrm{e}}$ Department of Cardiothoracic Surgery, Allina Health, Saint Paul, Minn; ${ }^{\mathrm{f}}$ Department of Cardiothoracic Surgery, Lenox Hill Hospital, New York, NY; ${ }^{\mathrm{g}}$ Department of Cardiothoracic Surgery, Temple University, Philadelphia, Pa; ${ }^{\mathrm{h}}$ Department of Cardiothoracic Surgery, Mayo Clinic, Jacksonville, Fla; ${ }^{\mathrm{i}}$ Department of Cardiothoracic Surgery, Franciscan St. Francis Health, Indianapolis, Ind; and ${ }^{\mathrm{j}}$ Department of Cardiothoracic Surgery, University of Toledo, Toledo, Ohio.

Sponsored and funded by Zimmer Biomet, Inc. The study sponsor participated in the design of the study and the collection and analysis of data. The authors had full freedom to explore the data and analyze the results independently from the sponsor.
}

in the management of fractures and osteotomies adhere to the principles of approximation, compression, and stabilization of the bone using rigid fixation, the vast

Clinical Trial Registry Number: clinicaltrials.gov (NCT01783483).

Read at the 96th Annual Meeting of The American Association for Thoracic Surgery, May 14-18, 2016, Baltimore, Maryland.

Received for publication June 24, 2016; revisions received Oct 11, 2016; accepted for publication Oct 12, 2016; available ahead of print Dec 4, 2016.

Address for reprints: Keith B. Allen, MD, 4320 Wornall Rd, Medical Plaza II, Suite 50, Kansas City, MO 64111 (E-mail: Kallen2340@aol.com). $0022-5223$

Copyright (C) 2016 by The American Association for Thoracic Surgery. Published by Elsevier Inc. This is an open access article under the CC BY-NC-ND license (http:// creativecommons.org/licenses/by-nc-nd/4.0/). http://dx.doi.org/10.1016/j.jtcvs.2016.10.093 

Abbreviations and Acronyms
BMI = body mass index
$\mathrm{CI}=$ confidence interval
$\mathrm{CT}=$ computed tomography
DSWI $=$ deep sternal wound infection
$\mathrm{OR}=$ odds ratio
$\mathrm{RCT}=$ randomized controlled trial
$\mathrm{RPF}=$ rigid plate fixation
STS = Society of Thoracic Surgeons
$\mathrm{WC}=$ wire cerclage

\section{Scanning this QR code will take}

you to a video and appendix for

the article.

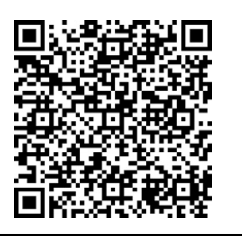

majority of cardiac surgeons continue to use wire cerclage (WC) for sternotomy closure because of the perceived low rate of sternal wound complications and the low cost of wires.

Although wires are effective at sternal approximation, they do not provide rigid fixation, nor do they adequately prevent sternal movement and separation., ${ }^{2,3}$ Mechanical studies have demonstrated that rigid plate fixation (RPF) of the sternum results in superior mechanical properties compared with WC, and in nonrandomized trials RPF has been reported to improve clinical outcomes. ${ }^{4-10}$ Although deep sternal wound infection (DSWIs) are reported to occur at a $<1 \%$ rate, recent reports suggest sternal complications occur with a greater frequency, ranging from $0.7 \%$ to $11.1 \%$, and represent significant clinical and economic events that might be mitigated by modifying sternal closure techniques. ${ }^{11-18}$

In a randomized trial comparing $\mathrm{WC}$ with a previous generation of the RPF system used in the current study, Raman and colleagues ${ }^{19}$ demonstrated that the mechanical benefit of RPF translated into better sternal healing as measured by computed tomography (CT) and that postoperative pain was improved. The impact of improved sternal healing with RPF on other clinically significant endpoints and an analysis of health care-related costs after sternal closure with RPF, however, have not been reported previously. The objective of this study was to evaluate sternal healing, sternal complications, and health care-related costs after sternotomy closure with RPF or WC in a prospective, randomized, single-blinded, multicenter trial. This study hypothesized RPF leads to superior sternal healing via CT at 3 and 6 months.

\section{METHODS \\ Study Design}

This prospective, randomized, single-blinded, multicenter trial enrolled 236 patients undergoing elective cardiac surgery at 12 US centers between March 2013 and June 2015 (Appendix E1). Institutional review board approval was obtained at each site, and informed consent was obtained from each patient before enrollment. This study was sponsored by Zimmer Biomet, Jacksonville, Fla, and registered at clinicaltrials.gov (NCT01783483). Inclusion criteria included patients $\geq 18$ years of age undergoing elective cardiac surgery via a median sternotomy who were admitted to the hospital within 24 hours of surgery. Preoperative exclusion criteria included patients with a body mass index (BMI) $\geq 40$, severe chronic obstructive pulmonary disease as defined by the Society of Thoracic Surgeons (STS), an active infection, New York Heart Association class IV heart failure, dialysis-dependent renal failure, and chronic steroid or narcotics use. Some of these were excluded to reduce variability in costs from nonsternal-related postoperative complications, whereas others had already been evaluated in a previous, multicenter randomized controlled trial (RCT) in which the authors evaluated RPF. ${ }^{19}$ Intraoperative exclusion criteria included the use of nonresorbable hemostatic agents or any intraoperative condition that would preclude the use of either WC or RPF (poor bone quality, off-midline sternotomies, bleeding, surgical complications, etc).

Patients meeting pre- and intraoperative enrollment criteria were randomized to either RPF (SternaLock Blu, Zimmer Biomet, Jacksonville, Fla) or WC (Figure 1) at the completion of the cardiac surgical procedure and immediately before sternal closure. Patients were randomized in a 1:1 ratio with a schedule generated by the sponsor. Randomization was stratified by site with a fixed block size of 6 . Sites were blinded to the randomization scheme, and no site was to enroll $>25 \%$ of the total population. Patients were blinded to the method of sternal closure. St Luke's Mid America Heart Institute (Kansas City, Mo) served as the coordinating center for the study.

\section{Sternotomy Closure Technique}

For patients randomized to RPF, a prespecified technique that has been described previously was used (Video 1)., ${ }^{9,19}$ In summary, sternal thickness was measured at anticipated plate locations to select the appropriate screw lengths needed to engage the posterior sternal cortex. Three sternal wires were used to reduce the sternal halves, muscle/fascia was elevated off the sternum at the location of plate placement, and plates were contoured as needed. One plate was placed on the manubrium, 2 " $\mathrm{X}$ " plates were positioned on the sternal body, and self-drilling screws were placed and fully locked into the plates. Should emergent re-entry be required, cuttable cross sections of the sternal plates spanning the sternotomy can be cut with standard wire cutters, or in redo sternotomies, the screws may be backed out and the plates removed. The technique for sternal closure with WC was prespecified to require a minimum of 6 stainless-steel wires (either single or double stranded) but was otherwise per institutional/surgeon preference to allow for various wiring configurations. Closure technique of the suprasternal soft tissue and skin was at the surgeon's discretion. Sternal closure time was recorded and included the time to prepare, approximate, and fixate the sternal halves.

\section{Outcome Measures and Follow-up Schedule}

The primary endpoint of the study, sternal healing at 6 months, was determined by independent radiologists at a core laboratory (University of Chicago, Chicago, Ill) using CT scans and a validated method that has been described previously and shown to have a high level of inter- and intraobserver agreement. ${ }^{20}$ To summarize, 5 axial CT slices from a priori-defined anatomic locations were selected by one core laboratory radiologist for evaluation. To preserve blinding, the core laboratory radiologist attempted to select CT slices that did not reveal which method of closure was used. Two additional radiologists then independently scored 


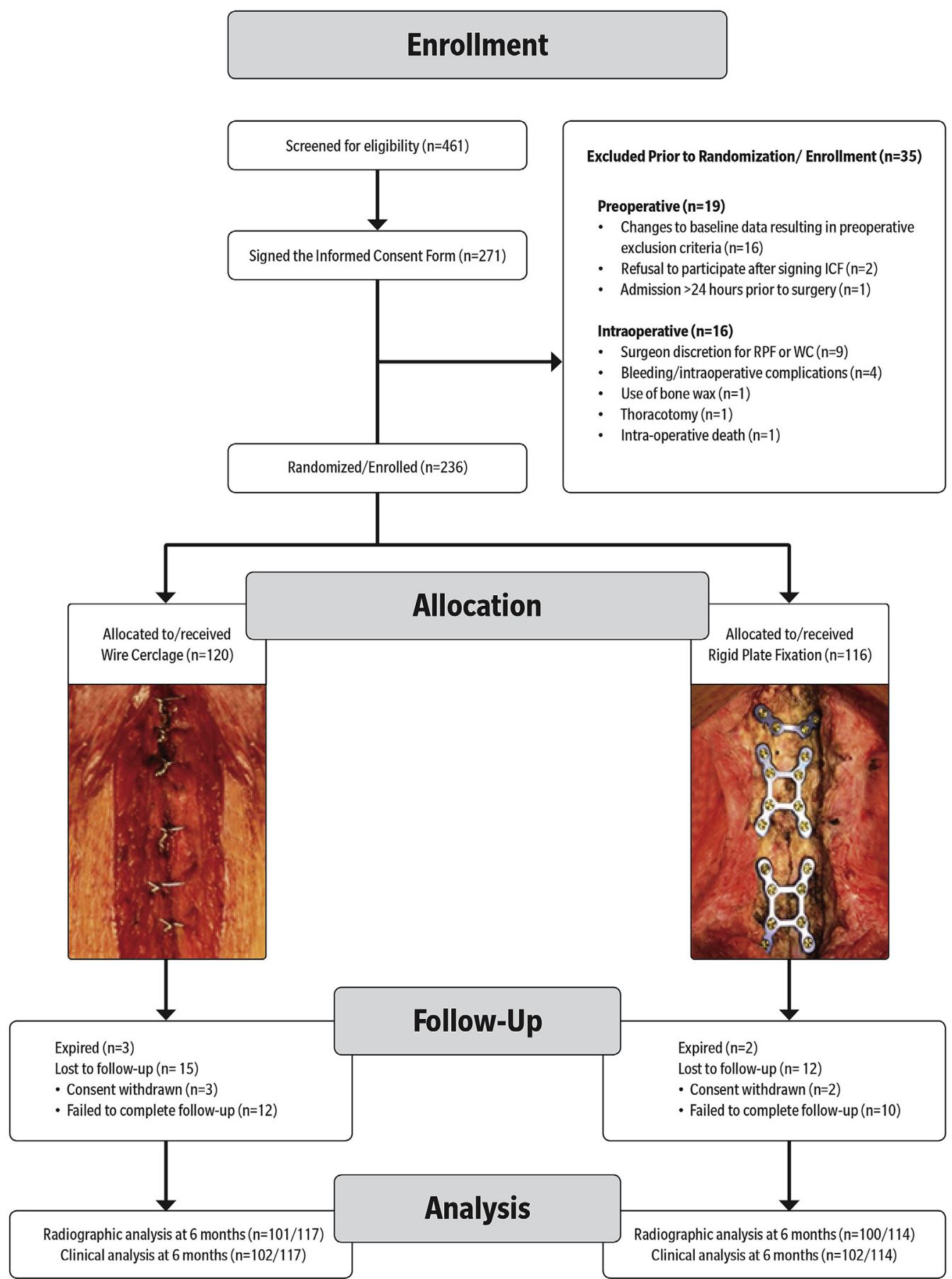

FIGURE 1. CONSORT (Consolidated Standards of Reporting Trials) diagram of patient enrollment and follow-up. ICF, Informed consent form; $R P F$, rigid plate fixation; $W C$, wire cerclage.

each location using a 6-point scale (greater scores represent greater healing), as shown in Figure 2. A mean score for each patient was determined, and sternal union was prespecified and defined as a mean score of $\geq 3$. ${ }^{19,20}$

Sternal complications were defined as any adverse event related to the method of sternal closure through 180 days and included deep or superficial wound infections as defined by the STS. All readmissions and reoperations, whether closure related or not, were recorded. Postoperative evaluations were performed during hospital admission and postdischarge at 3 weeks, 6 weeks, 3 months, and 6 months. Additional secondary endpoints, which will be reported separately, included pain scores, Short Form-36 quality of life assessments, and upper extremity functionality.

\section{Economic Analysis}

A health economics core laboratory (St Luke's Mid America Heart Institute) performed the economic analysis of RPF versus WC. Detailed 


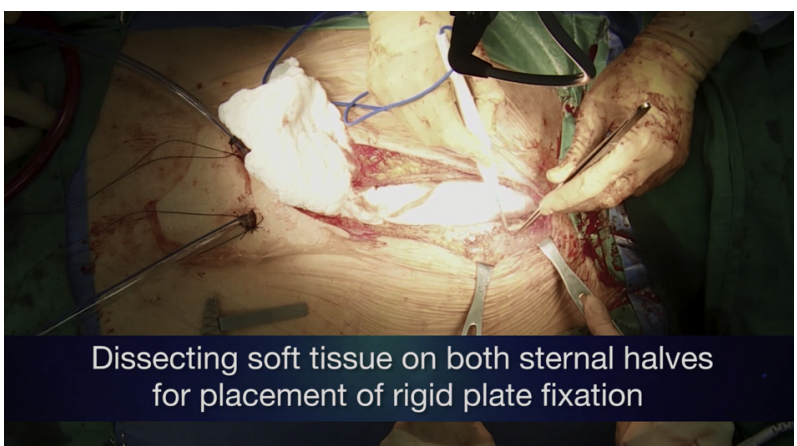

VIDEO 1. Surgical technique of sternotomy closure via the use of rigid plate fixation. Video available at: http://www.jtcvsonline.org/article/ S0022-5223(16)31503-3/addons.

medical resource use and hospital billing data were collected for all patients starting from the time of randomization (sternal closure) and continuing through 6-month follow-up. Health care costs were assessed for each patient from the perspective of the US health care system and expressed in 2014 US dollars. Specific methods for the cost analysis are described herein and were similar to those applied to economic analyses of drug-eluting coronary stents and transcatheter versus surgical aortic valve replacement. ${ }^{21-23}$

Index procedure and hospitalization costs. Costs for the index operation were calculated from the time of randomization, defined as the start of sternal closure. Prerandomization costs were not determined, as any differences would have been due to random statistical noise and not to the assigned method of sternal closure.

Detailed resource use (including the numbers of plates, screws, and wires) along with closure time were recorded for each patient, and costs were assigned based on the mean acquisition cost for each item. Costs for operating room time (including associated nonphysician personnel) were estimated by use of the mean cost per minute of operating room time at 3 study sites during the final year of the study.

For the remainder of the index hospitalization and any rehospitalizations during the follow-up period, costs were calculated from hospital bills by multiplying hospital charges by cost-center specific cost-to-charge ratios obtained from each hospital's Medicare cost report. To avoid "double counting" and to limit our analysis to costs incurred after randomization, itemized charges before randomization were removed from the billing data. The trial design, which excluded patients admitted greater than 24 hours before the index operation, was requested by the economics core laboratory to reduce variability of cost calculations. When bills were not available for the index hospitalization, costs were estimated with a linear regression model derived from those patients with billing data. When bills were not available for follow-up hospitalizations, costs were assigned based on mean national reimbursement rates for the appropriate Medicare severity-adjusted diagnosis related group.

Other costs. In addition to hospitalizations, enrolling sites collected data on rehabilitation facility stays, nursing home stays, and major outpatient resource use (emergency room visits, physician and allied health provider visits). These costs were estimated with the use of national averages (per diem rates for residential care and the Medicare fee schedule for outpatient services). Physician fees during the index hospitalization were assigned based on intensive care unit and nonintensive care unit length of stay; for follow-up hospitalizations, we assumed that physician fees would be equal to $20 \%$ of the hospital cost for the admission. ${ }^{24}$ Physician fees for the index operation were not included because those costs occurred before randomization.

\section{Statistical Analysis}

The trial was designed to test a superiority hypothesis of improved sternal healing. Assuming an attrition rate of $18 \%$ and an $\alpha=0.05$, a total sample size of 236 patients resulted in a power of $99 \%$ to detect a mean difference of 0.9 or larger in the bone healing score.

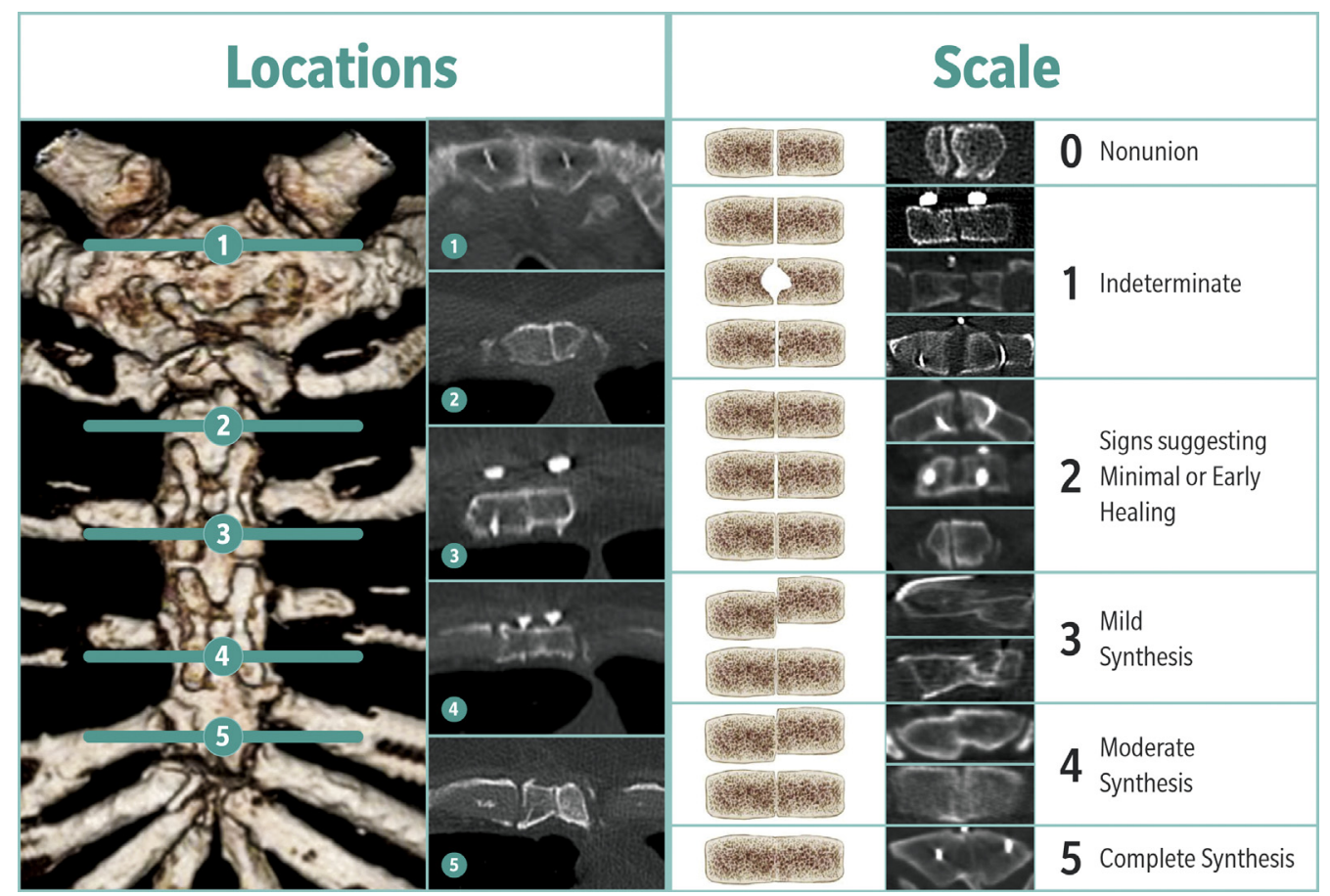

FIGURE 2. Computed tomography methodology for evaluating the primary endpoint, sternal healing. Axial sections were selected from 5 a priori-defined locations and then scored independently by 2 radiologists via a 6-point scale. 
Statistical analyses were prespecified and performed on an intent-to-treat basis. The primary endpoint, mean CT scan score at 6 months, was evaluated with a mixed model for repeated measures (MMRM, SAS Proc Mixed, Version 9.4; SAS Institute, Inc, Cary, NC), which uses implicit imputation of missing data. Analysis of sternal healing scores also was completed after we adjusted for a set of 15 baseline covariates (BMI, age, smoking, peripheral artery disease, chronic lung disease, sex, race, hypertension, cerebrovascular disease, diabetes, previous sternotomy, coronary artery bypass grafting, valve, operating room time, and closure time).

The same 15 covariates were evaluated as independent risk factors for reduced sternal healing scores via multiple linear regression at 3 and 6 months with backward stepwise regression. Treatment group was included in the model and not removed.

Continuous data, summarized and presented as a mean \pm standard deviation, were evaluated with $t$ tests. Categorical data, including complication rates, are summarized as a number (\%) and evaluated by the use of 2-sided Fisher exact tests.

Exact logistic regression was used to determine the variables predictive of sternal complications and infections. Covariates considered included method of closure (RPF or WC), diabetes, renal failure, smoking status, chronic obstructive pulmonary disease, previous sternotomy, bilateral internal mammary artery, age, sex, and BMI. The number of RPF patients needed to treat to prevent sternal complications was determined.

The primary economic outcome was total costs from the time of sternal closure through 6-month follow-up. Costs are described as mean values and were compared with nonparametric bootstrapping (1000 replicates). ${ }^{25}$ Bootstrapping cost variables is an accepted approach in economic analyses and is used for non-normally distributed data to determine whether there are differences in mean costs between treatment groups. For patients with incomplete 6-month follow-up, measures of resource use and cost were imputed for the missing time period based on their daily rates during the immediately previous time period.

\section{RESULTS \\ Recruitment, Baseline Demographics, and Operative Outcomes}

A total of 236 patients were randomized to either RPF $(\mathrm{n}=116)$ or WC $(\mathrm{n}=120)$. Excluding patient deaths, $89.5 \%(102 / 114)$ of eligible RPF and $87.2 \%(102 / 117)$ of eligible WC patients completed follow-up at 6 months. A description of patient enrollment and follow-up is shown in Figure 1.

Patients were similar with respect to baseline characteristics, surgical procedures performed, preoperative and intraoperative risk factors for sternal complications, and perioperative outcomes (Table 1). Although mean sternal closure times were longer in the RPF group compared with WC $(18.9 \pm 9.0$ minutes vs $16.3 \pm 9.3$ minutes; $P=.03)$, overall mean operative times were similar $(5.6 \pm 1.8$ hours vs $5.6 \pm 1.4$ hours; $P=.98)$.

\section{Sternal Healing}

Compared with WC, RPF resulted in better sternal healing scores at $3(2.6 \pm 1.1$ vs $1.8 \pm 1.0 ; P<.0001)$ and 6 months $(3.8 \pm 1.0$ vs $3.3 \pm 1.1 ; P=.0007)$ while also achieving greater rates of sternal union at 3 months $(41 \%$ [42/103] vs $16 \%$ [16/102]; $P<.0001)$ and 6 months $(80 \%$ [81/101] vs $67 \%$ [67/100]; $P=.03)$.
TABLE 1. Patient demographics, risk factors, and intraoperative and postoperative outcomes

\begin{tabular}{|c|c|c|c|}
\hline & $\begin{array}{l}\text { Rigid plate } \\
\text { fixation }\end{array}$ & WC & $\begin{array}{c}P \\
\text { value }\end{array}$ \\
\hline \multicolumn{4}{|l|}{ Demographics } \\
\hline Mean age, $y$ & $65.3 \pm 13.0$ & $65.7 \pm 11.4$ & .78 \\
\hline Sex distribution, male & $86(74.1 \%)$ & $91(75.8 \%)$ & .76 \\
\hline Height, $\mathrm{cm}$ & $172.2 \pm 9.8$ & $172.7 \pm 9.9$ & .65 \\
\hline Weight, kg & $85.6 \pm 17.6$ & $88.2 \pm 16.5$ & .23 \\
\hline BMI & $28.8 \pm 4.7$ & $29.4 \pm 4.6$ & .28 \\
\hline Race, white & $103(88.8 \%)$ & $103(85.7 \%)$ & .48 \\
\hline Hypertension & $86(74.1 \%)$ & $83(69.2 \%)$ & .40 \\
\hline Peripheral artery disease & $12(10.3 \%)$ & $5(4.2 \%)$ & .07 \\
\hline Cerebrovascular disease & $10(8.6 \%)$ & $7(5.8 \%)$ & .41 \\
\hline \multicolumn{4}{|c|}{ Risk factors for sternal complications } \\
\hline Diabetes & $35(30.2 \%)$ & $44(36.7 \%)$ & .29 \\
\hline $\mathrm{BMI} \geq 33$ & $26(22.4 \%)$ & $29(24.2 \%)$ & .75 \\
\hline Chronic lung disease & $22(19.0 \%)$ & $22(18.3 \%)$ & .58 \\
\hline Current tobacco use & $14(12.1 \%)$ & $10(8.3 \%)$ & .34 \\
\hline Renal failure & $0(0 \%)$ & $2(1.7 \%)$ & .16 \\
\hline BIMA & $7(6.0 \%)$ & $4(3.4 \%)$ & .37 \\
\hline Previous sternotomy & $8(6.9 \%)$ & $5(4.2 \%)$ & .36 \\
\hline \multicolumn{4}{|l|}{ Intraoperative variables } \\
\hline Isolated CABG & $56(48.3 \%)$ & $57(47.9 \%)$ & .95 \\
\hline Isolated valve & $33(28.5 \%)$ & $33(27.7 \%)$ & .90 \\
\hline CABG/valve & $25(21.6 \%)$ & $28(23.5 \%)$ & .72 \\
\hline Mean no. bypass grafts & $2.7 \pm 1.1$ & $2.9 \pm 1.1$ & .45 \\
\hline Operative time, $\mathrm{h}$ & $5.6 \pm 1.8$ & $5.6 \pm 1.4$ & .98 \\
\hline Sternal closure time, min & $18.9 \pm 9.0$ & $16.3 \pm 9.3$ & .03 \\
\hline \multicolumn{4}{|l|}{ Postoperative outcomes } \\
\hline Stroke & $0(0 \%)$ & $1(0.8 \%)$ & 1.0 \\
\hline Arrhythmia, any & $37(31.9 \%)$ & $40(33.3 \%)$ & .81 \\
\hline Acute renal failure & $0(0 \%)$ & $1(0.8 \%)$ & 1.0 \\
\hline $\begin{array}{l}\text { Reoperation for sternal } \\
\text { complications }\end{array}$ & $0(0 \%)$ & $6(5 \%)$ & .03 \\
\hline Reoperation for bleeding & $2(1.7 \%)$ & $2(1.7 \%)$ & 1.0 \\
\hline Length of stay, d & $6.9 \pm 2.4$ & $6.9 \pm 2.7$ & .92 \\
\hline Mortality, in hospital/30 d & $2(1.7 \%)$ & $2(1.7 \%)$ & 1.0 \\
\hline Mortality through 6 mo & $2(1.7 \%)$ & $3(2.5 \%) *$ & 1.0 \\
\hline
\end{tabular}

$W C$, Wire cerclage; $B M I$, body mass index; $B I M A$, bilateral internal mammary artery; $C A B G$, coronary artery bypass grafting. *One mortality in the WC group occurred in a patient presenting with a DSWI after 30 days.

Based on multiple linear regression, factors independently associated with reduced sternal healing at both 3 and 6 months included increased age (per 10 years), increasing BMI (per $5 \mathrm{~kg} / \mathrm{m}^{2}$ ), and current smoker (Table 2). After we adjusted for these factors, RPF (vs WC) was associated with an increase in sternal healing scores of 0.68 (95\% confidence interval $[95 \% \mathrm{CI}], 0.41-0.95$; $P<.0001)$ at 3 months and $0.47(95 \% \mathrm{CI}, 0.19-0.75$; $P=.001)$ at 6 months.

\section{Sternal Complications}

Sternal complications through 6 months were less frequent in RPF compared with WC patients $(0 \%$ [0/116] vs $5 \%[6 / 120] ; P=.03$ ), with a trend towards fewer sternal 
TABLE 2. CT scan assessment of sternal healing and predictors of sternal healing scores

\begin{tabular}{|c|c|c|c|c|c|c|}
\hline \multirow[b]{2}{*}{ Sternal healing } & \multicolumn{3}{|c|}{3 mo } & \multicolumn{3}{|c|}{$6 \mathrm{mo}$} \\
\hline & $\begin{array}{l}\text { Rigid plate fixation, } \\
\mathrm{n}=\mathbf{1 0 3}\end{array}$ & $\begin{array}{c}\text { Wire cerclage, } \\
\mathrm{n}=102\end{array}$ & $P$ value & $\begin{array}{c}\text { Rigid plate fixation, } \\
\mathrm{n}=101\end{array}$ & $\begin{array}{c}\text { Wire cerclage, } \\
\mathbf{n}=\mathbf{1 0 0}\end{array}$ & $P$ value \\
\hline Sternal healing score & $2.6 \pm 1.1$ & $1.8 \pm 1.0$ & $<.0001$ & $3.8 \pm 1.0$ & $3.3 \pm 1.1$ & .0007 \\
\hline \multirow[t]{2}{*}{ Sternal union rate } & $42(40.8 \%)$ & $16(15.7 \%)$ & $<.0001$ & $81(80.2 \%)$ & $67(67.0 \%)$ & .03 \\
\hline & \multicolumn{3}{|c|}{ 3-mo regression* } & \multicolumn{3}{|c|}{ 6-mo regression* } \\
\hline Covariates $\dagger$ & Effect \pm SE & $P$ value & $95 \%$ CI & Effect $\pm \mathrm{SE}$ & $P$ value & $95 \%$ CI \\
\hline Rigid plate fixation & $0.79 \pm 0.14$ & $<.0001$ & {$[0.52,1.07]$} & $0.45 \pm 0.14$ & .002 & {$[0.17,0.73]$} \\
\hline Greater BMI (per $5 \mathrm{~kg} / \mathrm{m}^{2}$ ) & $-0.20 \pm 0.07$ & .008 & {$[-0.35,-0.05]$} & $-0.28 \pm 0.08$ & $<.001$ & {$[-0.43,-0.13]$} \\
\hline Older age (per $10 \mathrm{y})$ & $-0.15 \pm 0.06$ & .012 & {$[-0.26,-0.03]$} & $-0.20 \pm 0.06$ & .001 & {$[-0.32,-0.09]$} \\
\hline Current smoker & $-0.62 \pm 0.26$ & .021 & {$[-1.13,-0.10]$} & $-0.63 \pm 0.25$ & .014 & {$[-1.13,-0.13]$} \\
\hline Peripheral artery disease & $-0.95 \pm 0.26$ & .000 & {$[-1.46,-0.44]$} & & & \\
\hline Chronic lung disease & $0.48 \pm 0.18$ & .011 & {$[0.11,0.84]$} & & & \\
\hline Male sex & & & & $-0.49 \pm 0.17$ & .004 & {$[-0.82,-0.16]$} \\
\hline Race (white vs other) & & & & $0.54 \pm 0.23$ & .022 & {$[0.08,1.00]$} \\
\hline Operating room time, hours & & & & $-0.11 \pm 0.05$ & .043 & {$[-0.21,0.00]$} \\
\hline
\end{tabular}

wound infections $(0 \%[0 / 116]$ vs $4.2 \%[5 / 120] ; P=.06)$ (Figure 3). Of note, half of the sternal complications (including infections) occurred after 30 days (Figure 3). The in-hospital/30-day DSWI rate was $0 \%(0 / 116)$ with RPF compared with $1.7 \%(2 / 120)$ with WC. The in-hospital/30-day superficial sternal wound infection rate was $0 \%(0 / 116)$ with RPF compared with $0.8 \%(1 / 120)$ with WC. Sternal complications resulted in 6 readmissions in the WC group between postoperative day 8 and 169 and required an additional 94 days of hospital stay and 11 reoperations. The number needed to treat (Table 3) to prevent 1 sternal complication at 3 months was 24 $(90 \% \mathrm{CI}, 13.9-85.5)$ and at 6 months was $20(90 \% \mathrm{CI}$, 12.1-57.8).

In a multivariate exact logistic regression model, sternal closure with WC was the only predictor of sternal

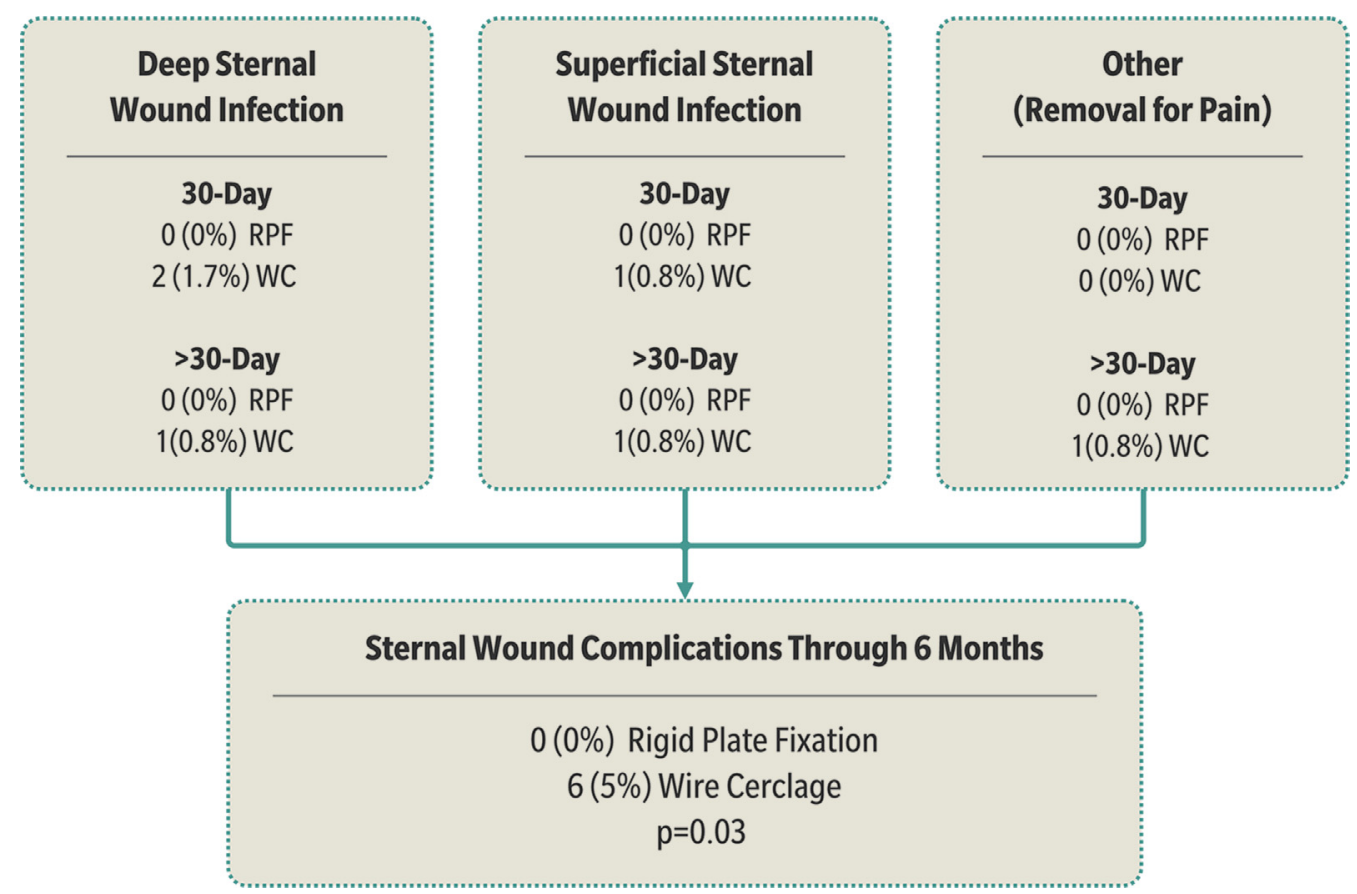

FIGURE 3. Six-month sternal complication rates. $R P F$, Rigid plate fixation; $W C$, wire cerclage. 
TABLE 3. NNT analysis to prevent sternal complications with the use of RPF

\begin{tabular}{cccc}
\hline Outcome & RPF vs WC & NNT* & $\mathbf{9 0} \% \mathbf{C I}+$ \\
\hline Sternal complications at 3 mo & $\begin{array}{c}0.0 \% \text { vs } 4.2 \% \\
(0 / 116 \text { vs } 5 / 120)\end{array}$ & 24 & $13.9-85.5$ \\
Sternal complications at 6 mo & $\begin{array}{c}0 \% \text { vs } 5 \% \\
(0 / 116 \text { vs } 6 / 120)\end{array}$ & 20 & $12.1-57.8$ \\
& &
\end{tabular}

$N N T$, Number needed to treat; $R P F$, rigid plate fixation; $W C$, wire cerclage; $C I$, confidence interval. *NNT represents the average number of patients who need to be treated to prevent one sternal nonunion or one sternal complication. $\nmid 90 \%$ normal theory CI for NNT determined by inverting the upper and lower bounds of the $90 \%$ 2-sided CI for the difference in percentages. The upper bound (UB) of the 2 sided $90 \% \mathrm{CI}$ is equivalent to the UB of a 1 -sided $95 \%$ CI. Therefore, the UB estimates the largest NNT (smallest effect size or clinical benefit) that is statistically consistent with the observed data.

complications (odds ratio $[\mathrm{OR}], 11.5 ; P=.02$ ) and sternal wound infections $(\mathrm{OR}, 10.7 ; P=.03)$. Although $\mathrm{BMI}$ was not a significant predictor, there was a trend towards increased sternal complications (OR 1.2 per unit increase BMI; $P=.10$ ) and wound infections (OR 1.2 per unit increase BMI; $P=.07$ ) in the WC group.

\section{Health Economic Endpoints}

Index hospitalization, follow-up, and aggregate 6-month costs are shown in Table 4. Initial hospital costs (assessed from the time of sternal closure) tended to be greater with RPF than WC $(\$ 23,437 \pm \$ 12,421$ vs $\$ 20,574 \pm \$ 14,102$; $P=.11$ ), driven by the cost of sternal plates and screws. Between discharge and 6-month follow-up, there was a trend toward lower costs with RPF as compared with WC $(\$ 9002 \pm \$ 18,041$ vs $\$ 13,511 \pm \$ 27,449 ; \quad P=.14$ ), which was related primarily to reduced readmissions, sternal complications, and outpatient resource use costs in the RPF group. Cumulative costs from randomization through 6-months were similar between groups $(\$ 32,439 \pm \$ 24,124$ vs $\$ 34,085 \pm \$ 30,916 ; P=.61)$.

\section{DISCUSSION}

Successful osteotomy and fracture management relies on bony approximation, compression, and stabilization for proper bone healing to occur. Biomechanical studies and superior clinical outcomes have resulted in the adoption of rigid fixation as standard of care in all specialties except cardiac surgery. ${ }^{26-28}$ Factors contributing to the continued use of WC for sternal closure include low cost, perceived low sternal complication rates, and a lack of prospective studies in cardiac surgery demonstrating clinical and economic benefits with RPF. This is the first prospective RCT to report on both clinical and economic outcomes in patients undergoing elective cardiac surgery after sternal closure with either RPF or WC. Compared with WC, patients treated with RPF had significantly better sternal healing and sternal union rates at 3 and 6 months and fewer sternal complications through 6 months' follow-up. Although RPF was associated with a trend toward greater index hospitalization costs, 6-month follow-up costs tended to be lower, resulting in similar total costs through 6-months.

Unlike an extremity fracture, which can be immobilized completely to prevent movement, the properties of the thoracic cage involving respiration and upper body movement create unique challenges during healing. Although WC provides lateral reduction during sternotomy closure, it fails to provide adequate stabilization to optimize sternal healing. ${ }^{19,29,30}$ Biomechanical studies have demonstrated that regardless of wiring technique, RPF provides superior stability. ${ }^{2,3,5}$ Raman and colleagues ${ }^{19}$ evaluated sternal healing with $\mathrm{CT}$ in a prospective RCT comparing WC with a first-generation RPF system (SternaLock, Zimmer Biomet, Jacksonville, Fla) and demonstrated better sternal healing with RPF. We confirmed these findings using the same CT methodology with a second-generation RPF system and further correlated this radiographic endpoint with the more clinically meaningful endpoint of fewer sternal complications.

Sternal complication rates after cardiac surgery, which include superficial and deep infections, range from $0.7 \%$ to $11.1 \% .^{11-17}$ These studies, which include both prospective and retrospectively collected data, encompass variable lengths of follow-up ranging from 30 days to 1 year. Databases such as the STS that typically track outcomes only to 30 days may actually underreport sternal complication rates, leading to the current perception held by many cardiac surgeons that sternal complication rates are low and that $\mathrm{WC}$ is adequate.

In a prospective study involving more than 7000 patients, Allen and colleagues ${ }^{31}$ reported that the median time to

TABLE 4. Index hospitalization, follow-up, and aggregate 6-month patient costs

\begin{tabular}{lcccc}
\hline & $\begin{array}{c}\text { RPF } \\
\text { costs per patient, } \$\end{array}$ & $\begin{array}{c}\text { WC } \\
\text { costs per patient, } \$\end{array}$ & RPF - WC difference & $\begin{array}{c}\text { Bootstrap } \\
\boldsymbol{P} \text { value }\end{array}$ \\
\hline $\begin{array}{l}\text { Total index } \\
\text { Hospitalization costs }\end{array}$ & $\$ 23,437 \pm \$ 12,421$ & $\$ 20,574 \pm \$ 14,102$ & $\$ 2863(-\$ 681, \$ 6103)$ \\
$\quad$ Total follow-up costs & $\$ 9002 \pm \$ 18,041$ & $\$ 13,511 \pm \$ 27,449$ & $-\$ 4509(-\$ 10,870, \$ 1207)$ \\
$\quad$ Total 6-mo costs & $\$ 32,439 \pm \$ 24,124$ & $\$ 34,085 \pm \$ 30,916$ & $-\$ 1646(-\$ 9127, \$ 4706)$ & .14 \\
\hline
\end{tabular}

Values shown are mean \pm standard deviation. The $95 \%$ confidence interval for the difference between RPF and WC is shown in parentheses. $R P F$, Rigid plate fixation; $W C$, wire cerclage. 
diagnose a DSWI/bacteremia infection after cardiac surgery was postoperative day 40 . Consistent with previous studies, we reported an overall sternal complication rate through 6 months after WC of $5 \%(2.5 \%$ at 30 days), which included a DSWI rate of $2.5 \%(1.7 \%$ at 30 days), with no sternal complications reported in the RPF group. Each of the 6 sternal complications occurred at 6 separate centers. These sternal complications represent significant morbidity and cost despite being relatively uncommon events. The average cost for rehospitalization for a sternal complication was $\$ 45,532$ in our study and comparable with the $\$ 62,000$ costs reported by Lazar and colleagues. ${ }^{17}$

Although the surgeon has limited control over patient risk factors, the method of sternal closure is one factor that can be controlled in an effort to enhance stability and reduce complications. The use of RPF mitigated traditional risk factors for sternal complications, with WC being the only independent predictor of both sternal complications and infections. The use of enhanced sternal stabilization to potentially reduce the risk of sternal infections, particularly in high-risk patients, recently was recognized by the STS Practice Guidelines and an expert consensus by Lazar and colleagues, where it was given a Level IIB recommendation..$^{17,32}$

Complications, particularly sternal infections, have come under increased scrutiny from payers and are now considered never-events by Medicare. Both government and commercial/private payers are transitioning to value-based reimbursement models, which will move providers from a fee-for-service toward a single payment to manage patient care over a specified period of time. ${ }^{33}$ As a result of these changes, the paradigm for cardiothoracic surgeons will shift to provide optimal patient care in a cost-effective manner not just for 30 days, but 90 or even 180 days. Expanded use of RPF will likely be driven by these changes, additional clinical and economic evidence, and patient awareness. Similar factors have contributed to the adoption of endoscopic vein harvesting, transcatheter valve therapies, and robotic surgery.

In the current health care environment, it is imperative that new technology, particularly one that adds initial cost, undergo a rigorous economic evaluation. Although the index operative and initial hospital costs tended to be greater with RPF compared with WC, costs between hospital discharge and 6-month follow-up tended to be lower $(P=.14)$, such that, overall, RPF was cost neutral through 6 months. From a health economic perspective, a treatment that improves outcomes without increasing costs is considered "economically dominant," indicating a high degree of economic value.

There are several limitations to the current study. The primary endpoint of this study was sternal healing based on CT evaluation by an independent core laboratory using a validated method..$^{20}$ One limitation was the inability to consistently blind the radiologists reading the CT scans as to treatment group allocation. Attempts were made to minimize bias by having one radiologist select CT slices from 5 a priori-defined locations and to choose areas that did not reveal the method of sternal closure. Two additional radiologists independently scored these slices with respect to sternal healing. Subject attrition was another limitation that was contemplated in the sample size calculation, which was powered for an $18 \%$ attrition rate. Despite the $11.4 \%$ (27/236) lost to follow-up rate at 6 months, the primary endpoint was proven. In addition, because the minimum clinically important difference in the mean CT scan score has not been determined, a sternal union rate was predefined to determine the number of patients who had radiographic healing. Finally, although patients were blinded to treatment arm, surgeons were not blinded. Because all sternal complications resulted in reoperations, surgeon bias in evaluating these complications was not a factor. There were no sternal complications that did not require readmission/reoperation reported in either arm.

One question is whether the results can be generalized to other RPF systems. Many medical technologies exhibit a class effect; however, the engineered components specific to implants within that class can determine clinical outcomes (eg, pacemaker implantation rates with different transcatheter valves). To date, only 2 prospective RCTs have been conducted that compare RPF with WC. Because both were done with first- and second-generation devices from the same manufacturer, conclusions on the class effect of RPF systems cannot be made.

In a prospective, randomized, single-blinded, multicenter trial, sternotomy closure using RPF resulted in improved sternal healing and fewer sternal complications than conventional WC at no additional cost to the health care system at 6 months. Although the benefits of RPF are well established, this is the first RCT that correlates RPF with improved sternal healing and also improved clinical and economic outcomes.

\section{Conflict of Interest Statement}

Keith B. Allen, MD, discloses a consulting relationship and National PI with Zimmer Biomet; David Cohen, MD, discloses research funding for health economics core laboratory with Zimmer Biomet. All other authors have nothing to disclose with regard to commercial support. The authors had full control of the design of the study, methods used, outcome parameters and results, analysis of data, and production of the manuscript.

Statistical analysis was performed by Greg Maislin (Biomedical Statistical Consulting). Scott Stacy, MD (University of Chicago), oversaw the core laboratory analysis of all CT scans. 


\section{References}

1. Mozaffarian D, Benjamin EJ, Go AS, Arnett DK, Blaha MJ, Cushman M, et al. Heart disease and stroke statistics - 2015 update: a report from the American Heart Association. Circulation. 2015;131:e29-322.

2. Losanoff JE, Basson MD, Gruber SA, Huff H, Hsieh FH. Single wire versus double wire loops for median sternotomy closure: experimental biomechanical study using a human cadaveric model. Ann Thorac Surg. 2007; 84:1288-93.

3. Losanoff JE, Collier AD, Wagner-Mann CC, Richman BW, Huff H, Hsieh FH, et al. Biomechanical comparison of median sternotomy closures. Ann Thorac Surg. 2004;77:203-9.

4. Pai S, Gunja NJ, Dupak EL, McMahon NL, Coburn JC, Lalikos JF, et al. A mechanical study of rigid plate configurations for sternal fixation. Ann Biomed Engin. 2007;35:808-16.

5. Pai S, Gunja NJ, Dupak EL, McMahon NL, Roth TP, Lalikos JF, et al. In vitro comparison of wire and plate fixation for midline sternotomies. Ann Thorac Surg. 2005;80:962-8.

6. Raman J, Song DH, Bolotin G, Jeevanandam V. Sternal closure with titanium plate fixation — a paradigm shift in preventing mediastinitis. Interact Cardiovasc Thorac Surg. 2006;5:336-9.

7. Song DH, Lohman RF, Renucci JD, Jeevanandam V, Raman J. Primary sterna plating in high-risk patients prevents mediastinitis. Eur J Cardiothorac Surg. 2004;26:367-72

8. Lee JC, Raman J, Song DH. Primary sternal closure with titanium plate fixation: plastic surgery effecting a paradigm shift. Plastic Reconstr Surg. 2010;125: 1720-4.

9. Raman J, Straus D, Song DH. Rigid plate fixation of the sternum. Ann Thorac Surg. 2007;84:1056-8.

10. Snyder CW, Graham LA, Byers RE, Holman WL. Primary sternal plating to prevent sternal wound complications after cardiac surgery: early experience and patterns of failure. Interact Cardiovasc Thorac Surg. 2009;9:763-6.

11. Shahian DM, O'Brien SM, Filardo G, Ferraris VA, Haan CK, Rich JB, et al. The Society of Thoracic Surgeons 2008 cardiac surgery risk models: part 3-valve plus coronary artery bypass grafting surgery. Ann Thorac Surg. 2009;88(1 suppl):S43-62.

12. Shahian DM, O'Brien SM, Filardo G, Ferraris VA, Haan CK, Rich JB, et al. The Society of Thoracic Surgeons 2008 cardiac surgery risk models: part 1-coronary artery bypass grafting surgery. Ann Thorac Surg. 2009;88(1 suppl):S2-22.

13. De Paulis R, de Notaris S, Scaffa R, Nardella S, Zeitani J, Del Giudice C, et al. The effect of bilateral internal thoracic artery harvesting on superficial and deep sternal infection: The role of skeletonization. J Thorac Cardiovascr Surg. 2005; 129:536-43

14. Crabtree TD, Codd JE, Fraser VJ, Bailey MS, Olsen MA, Damiano RJ Jr. Multivariate analysis of risk factors for deep and superficial sternal infection after coronary artery bypass grafting at a tertiary care medical center. Semin Thorac Cardiovasc Surg. 2004; 16:53-61.

15. Stelly MM, Rodning CB, Stelly TC. Reduction in deep sternal wound infection with use of a peristernal cable-tie closure system: a retrospective case series. $J$ Thorac Cardiovascr Surg. 2015;10:166.

16. Benedetto U, Altman DG, Gerry S, Gray A, Lees B, Pawlaczyk R, et al. Pedicled and skeletonized single and bilateral internal thoracic artery grafts and the incidence of sternal wound complications: Insights from the Arterial Revascularization Trial. J Thorac Cardiovasc Surg. 2016;152: 270-6.

17. Lazar HL, Vander Salm T, Engelman R, Orgill D, Gordon S. Prevention and management of sternal wound infections. J Thorac Cardiovascr Surg. 2016; $152: 962-72$
18. Graf K, Ott E, Vonberg RP, Kuehn C, Haverich A, Chaberny IF. Economic aspects of deep sternal wound infections. Eur J Cardiothorac Surg. 2010;37: 893-6.

19. Raman J, Lehmann S, Zehr K, De Guzman BJ, Aklog L, Garrett HE, et al. Sternal closure with rigid plate fixation versus wire closure: a randomized controlled multicenter trial. Ann Thorac Surg. 2012;94:1854-61.

20. Stacy GS, Ahmed O, Richardson A, Hatcher BM, MacMahon H, Raman J Evaluation of sternal bone healing with computed tomography and a quantitative scoring algorithm. Open Medical Imaging J. 2014;8:29-35.

21. Cohen DJ, Bakhai A, Shi C, Githiora L, Lavelle T, Berezin RH, et al. Cost-effectiveness of sirolimus-eluting stents for treatment of complex coronary stenoses: results from the Sirolimus-Eluting Balloon Expandable Stent in the Treatment of Patients With De Novo Native Coronary Artery Lesions (SIRIUS) trial. Circulation. 2004;110:508-14

22. Reynolds MR, Lei Y, Wang K, Chinnakondepalli K, Vilain KA, Magnuson EA, et al. Cost-effectiveness of transcatheter aortic valve replacement with a self-expanding prosthesis versus surgical aortic valve replacement. J Am Coll Cardiol. 2016;67:29-38

23. Reynolds MR, Magnuson EA, Lei Y, Wang K, Vilain K, Li H, et al. Cost-effectiveness of transcatheter aortic valve replacement compared with surgical aortic valve replacement in high-risk patients with severe aortic stenosis: results of the PARTNER (Placement of Aortic Transcatheter Valves) trial (Cohort A). J Am Coll Cardiol. 2012;60:2683-92.

24. Smith MW, Barnett PG, Phibbs CS, Wagner TH. Microcost Methods for Determining VA Healthcare Costs. Menlo Park, CA: Health Economics Resource Center; 2010.

25. Efron B, Tibshirani RJ. An Introduction to the Bootstrap. New York, NY: Chapman \& Hall; 1993.

26. Uhthoff HK, Poitras P, Backman DS. Internal plate fixation of fractures: short history and recent developments. J Orthop Sci. 2006;11:118-26.

27. Isley MR, Zhang XF, Balzer JR, Leppanen RE. Current trends in pedicle screw stimulation techniques: lumbosacral, thoracic, and cervical levels. Neurodiagnostic J. 2012;52:100-75.

28. Freeland AE, Luber KT. Biomechanics and biology of plate fixation of distal radius fractures. Hand Clin. 2005;21:329-39.

29. Matsuyama K, Kuinose M, Koizumi N, Iwasaki T, Toguchi K, Ogino H. Sternal closure by rigid plate fixation in off-pump coronary artery bypass grafting: a comparative study. J Artif Organs. 2016;19:175-8.

30. Nishimura T, Kurihara C, Sakano Y, Kyo S. Sternalock plating system for elderly post-sternotomy patients. J Artif Organs. 2014;17:288-90.

31. Allen KB, Fowler VG, Gammie JS, Hartzel JS, Onorato MT, DiNubile MJ, et al. Staphylococcus aureus infections after elective cardiothoracic surgery: observations from an international randomized placebo-controlled trial of an investigational $S$ aureus vaccine. Open Forum Infect Dis. 2014;1:ofu071.

32. Aldea GS, Bakaeen FG, Pal J, Fremes S, Head SJ, Sabik J, et al The Society of Thoracic Surgeons Clinical Practice Guidelines on Arterial Conduits for Coronary Artery Bypass Grafting. Ann Thorac Surg. 2016;101: $801-9$.

33. Shroyer AL, Bakaeen F, Shahian DM, Carr BM, Prager RL, Jacobs JP, et al. The Society of Thoracic Surgeons Adult Cardiac Surgery Database: The Driving Force for Improvement in Cardiac Surgery. Semin Thorac Cardiovasc Surg. $2015 ; 27: 144-51$.

Key Words: sternal closure, sternal complication, sternal wound infection, cost effectiveness, rigid plate fixation, wire cerclage, sternal healing 
APPENDIX E1. Study sites, investigators, and subjects enrolled per site

\begin{tabular}{|c|c|c|}
\hline Study site & $\begin{array}{c}\text { Principal } \\
\text { investigator }\end{array}$ & Subjects \\
\hline $\begin{array}{l}\text { St. Luke's Hospital, Kansas } \\
\text { City, Mo }\end{array}$ & Keith B. Allen, MD & 38 \\
\hline $\begin{array}{l}\text { University of Louisville, } \\
\text { Louisville, Ky }\end{array}$ & Kendra Grubb, MD & 35 \\
\hline $\begin{array}{l}\text { Columbia University Med Center, } \\
\text { New York, NY }\end{array}$ & Yoshifumi Naka, MD & 32 \\
\hline Allina Health, St Paul, Minn & John Grehan, MD, PhD & 31 \\
\hline Emory University, Atlanta, Ga & Vinod Thourani, MD & 26 \\
\hline Lenox Hill Hospital, New York, NY & Nirav C. Patel, MD & 22 \\
\hline $\begin{array}{l}\text { Franciscan St. Francis, } \\
\text { Indianapolis, Ind }\end{array}$ & Marc Gerdisch, MD & 16 \\
\hline $\begin{array}{l}\text { Temple University Hospital, } \\
\text { Philadelphia, } \mathrm{Pa}\end{array}$ & T. Sloane Guy, MD & 15 \\
\hline Mayo Clinic, Jacksonville, Fla & Kevin Landolfo, MD & 11 \\
\hline University of Toledo, Toledo, Ohio & Mark Bonnell, MD & 5 \\
\hline $\begin{array}{l}\text { Scott \& White Hospital, } \\
\text { Temple, Tex }\end{array}$ & Basar Sareyyupoglu, MD & 4 \\
\hline $\begin{array}{l}\text { Florida Hospital-Orlando, } \\
\text { Orlando, Fla }\end{array}$ & Donald M. Botta, MD & 1 \\
\hline
\end{tabular}

